\title{
Thoughts on Personnel Training Program of Environmental Design Majors in Comprehensive Universities in the Mid-west of China in the New Period
}

\author{
Tianshun $\mathrm{Hu}$ \\ Huanghe Science and Technology College \\ Zhengzhou, China
}

\author{
Yunjia Wei \\ Minsheng College \\ Henan University \\ Kaifeng, China
}

\begin{abstract}
The development of personnel training program in the new era is related to the future of the students, the future of the major, the future of the school and the future of the country. It is the fundamental problem that the country needs to solve at this stage. According to the different levels of basic education and education development in East, Middle and West of China, after nearly two decades development, the environment design profession has exposed different problems. In the background of the national proposal, the training program for environmental design needs to be revised and adjusted, and we should make it combine with the resources and conditions of central region to make it more suitable for the environmental design professional development of comprehensive universities in central area and also in line with national development needs of qualified personnel.
\end{abstract}

Keywords-Mid-west regions; environmental design; personnel training

\section{INTRODUCTION}

In September 2014 at the Davos Forum in Switzerland, China's premier of the State Council Comrade Li Keqiang put forward the "mass start-ups, mass innovation" slogan, since the "Shuang Chuang" the word became popular across the country, set off an unprecedented nationwide innovation and start-up climax. Environmental design and urban planning, architectural design major are the important component of the construction of innovative national design talents, in most of universities and colleges of central region have already set up environmental design major, and also attract more and more people's attention. With the continuous development of the economy, it is an important task for colleges and universities to cultivate innovative talents suitable in Shuang chuang background.

\section{DEVELOPMENT OF ENVIRONMENTAL DESIGN MAJOR IN COMPREHENSIVE UNIVERSITIES OF CENTRAL AND WESTERN REGIONS}

Environmental design major in colleges and universities of the central and western regions of China has nearly two decades of development. From the perspective of the whole education system, the scale of development has begun to take shape, but the major development in the central and western regions is obviously affected by the geographical location, the level of students is uneven, education and teaching environment is not ideal, personnel training mode is single, the curriculum system setting is also presented homogenization phenomenon in different degrees, it can not meet the huge demands of this major from society. With the development of market economy, the talent requirement for environmental design major increasingly high, environmental design is a profession with very comprehensive discipline, professional practice and application are very strong, covering a wide range of areas including architecture design, landscape design, garden design, interior design, furniture design, display design and many other content, emphasizing the realization of creativity, but also stressed the rational thinking to achieve many functions, in the meantime it required the students should have their own unique understandings and ideas for life, society and culture and is able to apply into their designs. From the current environmental design curriculum system can be seen that the professional training of personnel is mainly to emphasize the practicality, emphasizing social integration, after graduation can directly generate value, but the actual implement effect is not very satisfactory, which have students' individual reasons, but also there are some problems in the personnel training mode. "Innovative" type of talent as the goal, how to train innovative talents? We need to explore and research on personnel training mode and teaching methods.

\section{A. Environmental Design Professional Setting}

At present, most colleges and universities in China have opened environmental design major. In general it can be divided into the following categories: The first category is based on architecture and planning, the curriculum setting emphasis on student architectural history, student space building capacity development such as Tsinghua University, Tongji University, Southeast University and old five old architecture universities; The second category is based on plastic arts, focus on the students' appreciation and aesthetic 
ability, followed the traditional arts and crafts teaching model, professional Art university and Normal university who set up major early in the country such as the Central Academy of Fine Arts is the original Central Academy of Fine Arts, China Academy of Fine Arts, Xi'an Academy of Fine Arts, etc .; The third category is professional agricultural and forestry institutions based on Agriculture, horticulture, garden and other majors which has advantages in landscape ecology, plant landscape, new rural planning and other aspects, such as Nanjing Forestry University, Beijing Forestry University, China Agricultural University and so on. The fourth category is a comprehensive class institutions, mostly open major based on the national environment and the characteristics of the school. Due to the difference positions of personnel training program, there is no clear ambiguity in the students' orientation, and there is no other school environment that the other three categories institutions can rely on, so there will be a lot of shortages for the development in curriculum setting, teaching content and methods, training programs, resources, teaching ideas and methods. In summary, the central and western regions comprehensive institutions are very typical of the fourth category, due to the influence of local economic and geographical factors, although the major set up and the number of students have reached a certain height, but its own development did not established a good training environment, did not integrated with the local economic development and regional culture, thus making the number of people in education and social needs not match.

\section{B. Training Programs}

There are two prominent problems in the development of environmental design major in the comprehensive colleges in central and western regions:

1) The teaching content is obsolete, personnel training programs are similar and the target is too high: In teaching, generally speaking university teachers are master's degree or above, or the old teachers for many years, teachers' knowledge structure is formed in the past disciplinary system, in the new period will inevitably bring new requirements. For the current development situation of design and the understanding of popular view, the central region comprehensive university's teachers' knowledge become limited, and the support of comprehensive institutions for environmental design major is relatively limited, thus making teaching design content us lack of pertinence, lack of practical experience of theoretical knowledge, resulting in students do not attach importance to the understanding of professional theoretical knowledge, understanding of theoretical knowledge is not clear. Comprehensive institutions tend to focus on performance, despise practice, classroom teaching is greater than counseling practice, and the assessment of teachers is concentrated in the classroom teaching rather than practice counseling, resulting in students' practice process became just a form. Some teachers are too advanced for the design of teaching situations, students do not have real social perception and experience, during the design even they conduct the research and analysis but often struggling to cope, the teaching effectiveness of training did not achieve the real purpose. Such as a course in environmental design major Commercial space design, some teachers' work environment is defined as a five-star hotel customer service design, such space for most students are lack of life experience, and the students because of hotel management and other factors can not get a good study experience, then this design task is unsuccessful. Students in the learning stage can not learn anything, but the combination of design tasks and life experience will have more design basis Such as the design task for commercial space design change to commercial store space or dining space design, then students' audience base is more extensive.

2) Curriculum content is vague, similar, copy the framework system: When comprehensive institutions setting courses for environmental design major, theoretical courses account for a large proportion, professional teaching materials lags behind the social development, such as decorative materials and structural courses, material updates with each passing day, and has certain popular features, far beyond those in the books can be summarized. A set of training program at least used for four years, although it will be revised every year, but only a small range of changes, not from top-level to design the positioning of environmental design students, which resulting in regular revision has become tasteless, with no real effect. Students cannot grasp the design theory well and their absorption capacity of cutting-edge design ideas is weak too, only very few students take the initiative to learn, coupled with the students stay away from their parents' shackles, professional courses assimilation makes the trained students lack of self-confidence for their profession. They learned everything but good at nothing.

\section{Resource Conditions}

With the popularization of higher education and the development of economy, the advancement of environment design major of comprehensive colleges in central and western China has been affected by faculties, hardware and software, and geographical location, especially more prominent in some economically and culturally backward cities from the northwest of China. From the faculties in the middle and western comprehensive colleges and universities, most of the early teachers in environmental design major are mainly from arts and crafts or fine arts. In recent years, they have gradually transformed into design classes. Although the number and composition of teachers has been improved, but these teachers tend to be relatively young, most of them enter the classroom teaching just after graduate, from school to school, fresh graduates and Ph.D. graduates without real business practice in company, so they focus theory not practice during the teaching process, too theoretical and the content of teaching is not real. Students' practical ability and innovation ability can not got a good guide which become the criticize trouble to stop the professional development.

\section{Supply and Demand Imbalance}

From the employment situation of environmental design major, the situation is not satisfactory. Students tend to expect higher salary, but their ability is limited. Comprehensive institutions employment destinations are mainly with the following aspects. The first is to find a small company to work, from the early telephone marketing, project development, 
design to the budget to the construction, will experience every process. The second is to apply for the design position in construction company, engaged in one process of design, such as drawing effect diagram and construction diagram, or engaged in project supervision, materials, construction workers, design management and such positions. The third is to obtain the master's degree in order better study the environment design and have deeper understanding for the profession. The fourth is directly engaged in other industries after graduation. However, the first two have poor salary treatment, students tend to lose confidence quickly, struggling to cope with things and problems they have to deal with everyday. Only few of them could carry on. Colleges and universities focus on the art temperament and theoretical knowledge, but the society pay more attention to students' practical ability, practice and theory can not be balanced. In addition, personnel training in the central and western comprehensive institutions did not coordinated with regional economic development is also an important reason for the imbalance between supply and demand.

\section{Thoughts About the Personnel Training PROGRAM FOR ENVIRONMENTAL DESIGN IN CENTRAL AND WESTERN REGIONS}

Under the macroeconomic policy background of "Mass start-ups, mass innovation", it brings a favorable external environment and support to the development of the middle and western comprehensive colleges. The city planning and development, infrastructure construction will have a large number of talent demands. The integration of regional culture promoted the prosperity of cultural and creative industries and the development of tourism resources, the flow of talent makes education ideas, educational concepts to update, so that environmental design major and the local economy could make better integration and provide better service to the community. These are the development opportunities for environmental design major.

The biggest problem of the environment design personnel training in the middle and western comprehensive universities is that the orientation of training programs is ambiguous. Under the new situation, about how to grasp the direction of personnel training, we should fundamentally change the training mode.

\section{A. Determine the Objectives of the Training Program}

1) Elite teaching: In order to achieve the elite teaching objectives, we should optimize the knowledge structure, develop the personnel training based on social demands, strengthen the training of teachers' practical ability and enhance the ideological level of design, encourage teachers to participate in practice, establish studio and do part-time company design works, so that to make elite teacher team and then make the students training into elites.

2) Application as the basis, innovation as the concept: In the background of "Mass start-ups, mass innovation", the school consider to add innovation and start-up into the evaluation system while setting up the new personnel training programs, through the whole process of personnel training.
Stimulate students' personality development and innovative spirit while studying professional knowledge. Through the rich classroom theory to the practice, then to the after-school cultural life, to build the innovative new training mode which ensures the knowledge, ability, and quality develop balanced. Let students to give full play to their own characteristics into profession, into life, thus inspiring students' thinking for profession and further enhance their social practice ability.

\section{B. Change of Teaching Content}

1) Strengthen the practice teaching, pay attention to the combination of art and science: Change the passive teaching mode in the past, take project as the main line of teaching, teachers for guidance, students as the main subject of the course, so that students take the initiative to participate in, to the class and make free collaborations. Such as teachers can integrate the characteristics of enterprise operation into teaching, when the design unit received the design task, before officially meet with the customer, design project is certainly to be completed. Let students complete with free combination groups, in this way not only practice students' design management ability, but also make them experienced the labor division from start to finish during the learning process. The training of team cooperation ability and time management ability will stimulate their professional ability of self-learning, thinking and improve the design ideas. So we should place students in the team, both as the leader and the complete person. Teachers in this process play the role of guidance and problem solvers, this project team teaching methods make classroom atmosphere active and alive, it is better to mobilize the enthusiasm of students, let them to express their designs better.

2) Build a comprehensive and harmonious integrated elite course system which is demand-oriented, capacity-based training and highlight the innovation: When designing the new training program, we should consider the inseparability of theory. In the depth of the design from basic design to professional design, to the final innovative design, gradually complete the innovation process, change the students' confusion when they set up different space design course in senior grade, which is after every design is finished, the design depth always stays in the shallow basic design layer. During the class teaching organization process, integrate design real project into the classroom, uninterrupted and repeated exercises in the four years learning process in order to truly implement the market-oriented curriculum training system.

\section{CONCLUSION}

To sum up, under the background of the current policy of "Shuang Chuang", the universities in the central and western regions should change the homogeneity problem faced by the current environmental design major. When set up the personnel training program, it must keep pace with the times and market demand-oriented, take capacity training as basis, innovation as the concept, so that actually make the personnel training program connect with society from the top design, and provide better service for the society. 


\section{REFERENCES}

[1] Liu Youyao, Jiang Lin, Du Huimin, Zhang Liguo, Gong Jiamin, Liu Jihong. "Research and practice on the training mode of engineering application type innovation talents" [J] Higher Engineering Education Research, 2015 (05).

[2] Zhang Xingquan, Sun Xinyi. "A study on the training mode of art design major in engineering colleges" [J]. Art Education Research, 2013 (4).

[3] Peng Song. "Exploration of innovative ability training system in animation major under the vision of Shuang Chuang" [J]. Jixi University Journal, 2016. 